\title{
Sexualized Branded Entertainment and the Male Consumer Gaze
}

\author{
Matthew P. McAllister ${ }^{*}$ and Lauren J. DeCarvalho** \\ Department of Film-Video \& Media Studies, Pennsylvania State University, University \\ Park, USA, mattmc@psu.edu \\ "Department of Communication, University of Arkansas, Fayetteville, USA, \\ ljdecarv@uark.edu
}

\begin{abstract}
Integrating work influenced by Erving Goffman and Laura Mulvey, this article applies the concept of the "male consumer gaze" to two branded US televised events, the 2011 Victoria's Secret Fashion Show and the 2012 Hooters International Swimsuit Pageant. Critiqued elements include gendered body positioning and placement, televisual and narrativizing techniques, social and integrated media, and branding strategies that combine to create a flow of consumption-based male gazing. Such trends may intensify with changes in media economics and niche marketing.
\end{abstract}

Keywords: Male Consumer Gaze, Branded Entertainment, Sexualization, Television, Advertising, Branding, Victoria's Secret, Hooters

Acknowledgement: A previous version of this manuscript was presented in the Feminist Scholarship Division of the International Communication Association, London, England, June, 2013. Thanks to the editors of this special issue for their vision and careful attention.

National Football League fans watching the US television network CBS's early-game broadcast on Sunday, November 27, 2011, were targeted by the usual male-oriented product advertising and program promotions. One second-quarter commercial break contained a promotion for an upcoming CBS special to air later in the week. Scored with intense rock music and audience cheers, a deep-voiced male announcer enthused, "Get ready. For the looks. The ladies. And the lingerie." Graphics with each of these phrases appeared as the announcer said them. Visual images of models in lingerie were edited to also synchronize with the words, with the first peeking coyly at the camera (signifying "the looks"), then a row of lingeried models ("The ladies"), and finally a bust shot of a diamond-encrusted bra ("And the lingerie."). A model says directly to a camera but behind a runway curtain, "Wow, this is small" as she gestures to her bra. "With musical guests Maroon 5," the announcer continues, as viewers see video footage of singer Adam Levine standing very close to a model, staring at her as he sings, while she looks ahead. ${ }^{1}$ Levine then gives the model a quick kiss to her shock. "Kanye West and Jay-Z," the announcer says, as both are shown together onstage, but in darkness. "And Nicki Minaj": the brightly costumed singer appears first in starkly lit extreme close-up, then next to a runway model in similar attire. The announcer concludes, "The Victoria's Secret Fashion Show. CBS. Tuesday, 10, 9 Central."

This on-air promotion serves not only to publicize the upcoming special, but also as a how-to guide instructing the mostly male football fans about tips for watching the program. The promotion emphasizes "the looks" of "the ladies" in "lingerie" (orally, verbally, and visually reinforced), the promise of access to behind-the-scenes - even taboo - images ("this is small"), the brightly lit females versus the more in-the-dark males (Minaj contrasted with

\footnotetext{
${ }^{1}$ Figures and illustrations accompanying this article may be accessed at: http://www.personal.psu.edu/users/m/p/mpm15/CCCMaleConsumerGazeFigureslllustrations.pdf .

2 Fans of Maroon 5 or The Voice - the reality show in which Levine appears - may have known at the time that he was dating this particular model, Anna Vyalitsyna. However, it is unclear if the typical NFL viewer made these connections.
} 
Kanye/Jay-Z), and even a celebrity performing the gaze itself à la Levine's unmitigated staring. In these ways, the promo also mirrored many of the gendered semiotics of the program itself and accompanying ads, and all in the service of the Victoria's Secret brand.

This article argues that the 2011 Victoria's Secret Fashion Show (VSFS) and a second branded television program, the 2012 Hooters International Swimsuit Pageant (HISP), enact a "male consumer gaze." Both programs combine several sexualized commercial and filmic techniques and strong ties to commodity branding. By analyzing these programs as well as accompanying advertising and media promotion, the article will advocate for the concept of the male consumer gaze to understand modern forms of gendered, commercialized visual culture.

\section{Building Toward a Conceptualization of the Male Consumer Gaze}

The highly gendered nature of product advertising - specifically the commercial subordination of women - is arguably one of the most replicated findings in all of media studies (for reviews, see Nowak, Abel, and deBruin 2010; Shields with Heinecken 2002). An early scholarly treatment was Goffman's 1979 book Gender Advertisements, described by Shields with Heinecken $(2002,36)$ as "one of the most influential textual analyses of the symbolic potential of advertising images." Focusing on gendered images in print ads, Goffman delineates ways that women are systematically subordinated, infantilized and sexualized in these images. His categories focus on the differences between men and women in terms of gestures, facial expression, body placement in the advertising's design, and body posture. Key terms from Goffman are the "feminine touch", "function ranking" and "ritualization of subordination." The "feminine touch" involves a feminized caress, such as self-touching in the form of fingers touching the open mouth in contrast to firm male grips. "Function ranking" shows males framed as more active and in higher organizational roles than the roles of females. "Ritualization of subordination" presents destabilizing vertical and horizontal body placement, canted head, knee, and body postures, and men physically looming over women.

Williamson (1978), at the same time as Goffman, noted the tendency of cosmetic ads to fragment women's bodies - such as eyes and lips into isolated parts (also cited in Andersen, 2002). As Shields with Heinecken (2002) argue, work has continued to criticize such qualities in advertising, including selective cropping, that emphasize sexualized (and sometimes seemingly dismembered) female body parts, such as "bodyism" (Hall and Crum 1994). Themes of violence and body thinness complement the ideological inequity of these trends (Nowak, Abel, and deBruin 2010), and critics such as Kilbourne (1999) highlight how written copy of advertising often reinforces objectifying themes in the visuals. Scholars continue to argue for the relevance of Goffman's analytical categories for understanding the ideology of gendered advertisements (The Codes of Gender, 2009; Rudy, Popova, and Linz 2011).

While the above work originates out of advertising criticism and focuses on the placement and characteristics of models in ads, another relevant line grew out of feminist film theory and spotlighted gendered cinematic technique. Of great influence was Mulvey's (1975) much-cited concept of the male gaze, situated in film because of camerawork and audience scopophilia, with the latter explicated both in terms of looking at something or someone erotically but also taking pleasure in being looked at. Narrative cinema creates three distinct "looks": that of the camera, of the audience, and of onscreen characters (Mulvey 1975, 17). Since camerawork denies the first two types of gaze, this results in the prominence of (male) onscreen characters' points of view (ibid., 17). Examples include panning up to signify a sexualized view of women's bodies, close-ups on a woman's breasts or rear, or slow motion to accentuate lingering upon a woman's body. Such cinematic techniques "connote to-belooked-at-ness" [italics in original] as a characteristic of onscreen women (ibid., 19). The male gaze involves more than the sexually voyeuristic one: it is an inherently power-laden concept, rooted in patriarchal aggression and control (Hocker Rushing 1998; Shields 1990). The concept has not been uncontended. Some scholars posit that Mulvey's concept is too essentialist, arguing for alternative conceptualizations such as the female masquerade 
(Doane 1982), female subjectivity (De Lauretis 1984), or the female spectator and gaze (Stacey 1987; Helford 2006).

Although Mulvey's original work centers on Hollywood cinema and is rooted in psychoanalytic theory, the concept of the male gaze has been applied to other forms of media. In such cases, the application of this concept is often used without any psychoanalytic underpinnings, emphasizing less audience motivation and pleasure than textual characteristics. Scholars have applied the male gaze concept to scripted television (Cooper 2001; Stern 2005; Middleton 2007), televised sports (Oates 2007), news and celebrity photography (Hocker Rushing 1998), and even radio (Foss and Foss 1994). Foss and Foss's analysis of how a nonvisual media product - the radio program A Prairie Home Companion - evokes, through its language, a female gaze is elucidating. It highlights the role of the verbal component in positioning the audience to adopt either a male or a female gaze.

The gaze concept may also be usefully applied to advertising, especially in television. The construction of a heterosexual male perspective, many critics argue, is true for both ads targeted for men and those targeted for women. In this context, Shields with Heinecken (2002) note that the male gaze complements Berger's (1972) earlier point that, in various forms of Western culture (including advertising), men are portrayed as looking at women, while women look at themselves being looked at (cf. Shields 1990). Thus, Andersen $(2002,224)$ argues that advertising and consumer culture portray "women as objects designed to attract the gaze, not only of men, but also of other women invited to emulate them." When ads use techniques to orient, reference, or imply a heterosexual male gaze, then these techniques serve several functions (to adapt a similar typology from Williamson 1978): to attract attention, to associate a brand with a lifestyle involving sexualized women, to promise that the brand will somehow attract sexualized women, or to promise to women consumers that the brand will allow them to be gazed upon favorably by (heterosexual) men. Amy-Chinn (2006) adds that state regulation tends to judge advertising as more objectionable when it evokes alternative sexualized gazes.

Some scholars have posited that the concept of the male gaze is not emphatic enough in addressing the sexualized nature of women in film, television, and especially advertising. Related concepts, such as the "pornographic gaze" (Merskin 2006), emphasize the steady proliferation of hypersexualized images in advertising as a "pornography of everyday life" (Caputi 1999, 58). Although the gaze metaphor is used, this perspective is often applied to print advertising and focuses on Goffmanesque body placement and nudity.

Just as there are debates about the rigidity of the cinematic male gaze, so are there multiple perspectives about the power of an advertising gaze to guide subjectivity. Scholars such as Patterson and Elliot (2002) stress the importance of the nontraditional male gaze in advertising, and of the potential agency in female gazing and sexual subjectivity (Gill 2008). However, the consumerist, individualist, and sexualized nature of postfeminist depictions of women in advertisements can also lead to representations of women displaying a self-objectifying stance, doing so in the name of (pseudo) agency and empowerment (Amy-Chinn 2006). This ultimately serves to shift the source of blame concerning objectification from the advertising industry's acceptance of the male gaze to women themselves. As Gill (2008) notes, although there may be legitimate issues of empowering sexual subjectivity in ads featuring the female "midriff," this "sexual subjectification" (ibid., 41) is mitigated by other power-laden social categories besides gender, including race, ability, age and class.

To combine the two main critical traditions reviewed above, we see then a Goffmanoriented perspective, centered specifically on advertising that emphasizes model body placement and visual and verbal indicators of gender subordination. This contrasts with the study of the male gaze, originally out of feminist film theory but also applied to several other media. This tradition highlights the gendered dynamics of cinematic techniques, such as editing and camera angles and characteristics more especially associated with advertising, including storytelling, slogans and logos, and the heavy use of graphics that can "instruct" or direct the gaze. The purpose of the present article is to integrate these approaches in its study of the "male consumer gaze." In such a perspective, elements of print media (model placement, gendered posture, facial expressions) are studied together with cinematic tech- 
niques, such as editing, camera angle, narration, and with specific textual qualities of advertising (logos, slogans, jingles, and graphics). These modalities may combine to ideologically reinforce the subject position of promotional discourse to that of the heterosexual male consumer.

An integrated concept such as the male consumer gaze may be especially useful since promotional and marketing efforts have both expanded, to include forms beyond the onepage print ad or the 30-second television commercial, and narrowed, as niche marketing focuses on highly defined - often gendered - markets.

\section{The Movement Toward Branded Entertainment}

With changes in advertising and media, including new technologies, media-use patterns and regulatory environments, scholars have noted an increase of intrusive advertising in different forms of culture (Andersen 2008; Baltruschat 2011; Bettig and Hall 2012; Lehu 2007). Part of a larger trend of hypercommercialism (Andersen 2008; McChesney 1999), such intrusive advertising takes several forms. One of them is branded entertainment where the premise of a media text is based on brand promotion. Branded entertainment is among the most highly commercialized forms of culture (Lehu 2007). Baltruschat $(2011,45)$ argues that "branded entertainment lies at the core of the new media economy." Its forms range from gaming such as "advergames" (Grimes 2013) to print media including "branded magazines" (Pfeiffer, 2012). Television versions include reality TV (such as the Trump-oriented The Apprentice) and, as will be discussed with VSFS and HISP, special events. Television production and distribution companies find branded programs attractive. They are advantageous both to curtail costs, as advertisers become more and earlier involved in the product process, and to increase advertising revenue. Advertisers, in turn, see programs created around their product as ways to stand out among commercial clutter. Such forms increase the presence of advertising in culture, hybridizing commercial tropes into media genres. They may combine consumption-friendly messages with other ideologies associated with advertising, such as gender.

Trends in Integrated Marketing Communications (IMC) and niche marketing further incentivize branded entertainment trends. IMC, the coordination of different promotional techniques, such as advertising, public relations, special events, sales promotion, helps to ensure the success of large-scale marketing efforts, including forms of branded entertainment. It has been further encouraged by the introduction of social media, such as YouTube, Facebook, and Twitter, which add to the promotional mix (Mulhern 2009).

From a cultural point of view, scholars have applied Williams's (1975) notion of television "flow" to argue that diverse forms of commercialism in modern television integrate into "commodity flows" of promotional messages that move from program to program promotion, to commercial, to public relations-oriented news, and beyond (Budd, Craig and Steinman 1999; McAllister and Giglio 2005). Niche marketing (Turow 2006) has also converged with branded entertainment. Such forms use targeted media, such as digital cable channels, websites, or mobile-phone apps, to reach especially desirable markets with specialized sales messages. Many niche-oriented brands highlight gender to establish brand distinctiveness. Product categories such as cosmetics and fashion are examples of forms in which gender differentiation is essential, but gendered sales pitches or brand images are also used for product categories normally positioned as gender neutral. Examples of the latter are the so-called "breastaurants" that integrate female sexualization into their brand image and retail spaces. Specific examples include the chains Twin Peaks, Tilted Kilt and of course Hooters (Morrison 2012). Narrowcast media and promotion may also serve the function of "hiding" messages that appeal to a very specific group. However, they would be objectionable to a general population, including highly stereotypical messages about gender.

How, then, might the concept of the male consumer gaze be applied to heavily gendered forms of televisual branded entertainment, especially given the flow of promotions, programs and commercials? 


\section{Description of Texts and Methods}

Limited Brands, the corporate parent of Victoria's Secret, owns several other brands in addition to its famed lingerie retailer. Among them are Victoria's Secret Pink, Bath and Body Works, La Senza, and Henri Bendel. However, revenue from Victoria's Secret comprises over $60 \%$ of total net sales for its parent company, especially through the more than 1,000 retail outlets worldwide (Annual Report 2012). Victoria's Secret also reaches customers via both its website and, more traditionally, its catalogue. In previous years, the latter functioned "for many of its consumers, as a kind of sexually explicit representation of the female body, not too far afield from Playboy's images" (Juffer 1996, 27-28). Kite (2011) argues that more recent VS media are illustrative of postfeminist ideologies by packaging self-objectification as empowering to women.

In 2001, the brand began televising its fashion show (Patches 2011), at first on ABC and later CBS. The 2011 VSFS brought in 10.3 million viewers (O'Connell 2011). Held at the Lexington Armory in New York City, the program was divided by themes that introduced new features, such as behind-the-scenes videos, or foreshadowed the designs worn by the models, such as "Super Angels," which offered superhero-themed lingerie. The program also featured a \$2.5 million Fantasy Treasure Bra worn by VS model (or "Angel") Miranda Kerr and musical performances from Kanye West, Maroon 5, Jay-Z, and Nicki Minaj. Part of a larger campaign, VSFS is promoted by both VS and CBS websites, as well as Facebook and Twitter. Ads for VS merchandise also air during the VSFS broadcast, although commercials for other brands are placed as well. The event receives extensive press attention, including advanced coverage on CBS's The Early Show, the morning news program of the network that airs the program. As one branding executive noted about the program, "because of the PR machine, people cover it likes [sic] it's news" (quoted in Guthrie 2011, § 25).

Hooters is a theme-based restaurant with over 400 franchises worldwide (Hooters Franchising 2012). In many ways, it is also a media brand, with much of its media highlighting "Hooters Girls": members of the chain's female waitstaff, known for their tight Hooterslogoed, low neckline white shirts and orange shorts. The brand's focus is traditionally on sports, beer, chicken wings, and female sexuality. Thus, it is mainly geared to a workingclass male clientele (Morrison 2012). Part of its marketing strategy is a heavy involvement with sports sponsorship, including a Hooters NASCAR car and a second-tier golf league. It also produces a branded magazine, television specials airing on basic cable television networks, a calendar, and a website with various Hooters-themed merchandise. HISP was a two-hour television special that aired on the US cable television network FX from $10 \mathrm{pm}$ to midnight EST, that is, during a male-oriented time slot. The lead-in was an Ultimate Fighting match. The Miami-based pageant was co-hosted by Mark McGrath, the lead singer for the rock band Sugar Ray, and the main host, and Sara Hoots, a previous Hooters pageant winner, who mostly appeared in backstage segments. One "Hooters Girl" was selected for the main crown from among one hundred contestants as well as for subordinate titles, such as "Miss Congeniality," "Miss World" (an international Hooters employee) and "Miss Photogenic." The eight judges were six men and two women: one of the female judges was a former Hooters Girl and Playboy Playmate, and the other a surfer. The male judges were a mix of sports stars and military personnel. The first half of the program focused on quick onstage introductions by McGrath of all one hundred contestants, while the second half highlighted the ten finalists and the winners. Besides cuts to backstage views and features, the program offered celebratory segments about the Hooters brand and corporation, video segments about how the contestants were selected, as well as segments featuring the previous winner and a few notable contestants. The program was heavily promoted with additional marketing materials, including web pages on both the Hooters and FX sites, press releases, YouTube videos, and a Facebook page. Similar to the VS special, commercials for other products were aired during the special, although Bud Light was the official sponsor of the broadcast, as announcers informed viewers before commercial breaks.

Both programs, then, were highly gendered displays centered on gendered brands. They were both supported with additional marketing forms, such as promotions, websites, social 
media, and featured advertising for other products. As such, the two programs are a kind of "übertext" that illustrates the many ways a male consumer gaze is enacted. In fact, there are essential differences between the two that may vary the nature of a male consumer gaze. One program purports to display commodities on bodies (VS lingerie), while the other was about the physicality of the branded body (Hooters Girls in swimsuits). Although both programs featured women on runways with a live audience, VSFS was a fashion exhibition, while HISP was a contest, with winners chosen. HISP thus had judges, while VSFS had celebrity musical performers.

The class markers of the two programs also varied. As a brand, Victoria's Secret has an image of petit bourgeois sexuality, while the chicken wings-oriented Hooters is directed more toward the blue-collar male clientele. One program featured celebrity fashion models and singers, while the other focused on working-class restaurant workers. VSFS displayed its celebrity audience, while the audience was rarely shown in HISP and was described by cohost Hoots as "hundreds of troops and their families." Comparing two lingerie catalogues, Valdivia (1997) highlights how class may frame mediated female sexuality with more upperclass catalogues, such as Victoria's Secret stressing leisure. On the other hand, workingclass publications, such as for Frederick's of Hollywood, may include more signifiers of active sexuality and varied body types.

To focus the analysis, the "sensitized concept" was applied, defined by Christians and Carey (1989) as the "taxonomical systems that discover an integrating scheme within the data themselves" (370). For the purpose of this project, sensitized concepts revolve around both the issues of the (male consumer) gaze as well as (sexualized) branding efforts. More specifically, sexualized televisual techniques, body postures, and visual metaphors in language and branding techniques focused the analysis.

The authors of this project independently viewed and took detailed notes about elements of the male consumer gaze for both main texts. These included the programs and the commercials airing during these programs. Each author commented on the other's notes. Postviewing discussions corroborated observed characteristics and interpretations. Supplementary marketing materials, such as images from Facebook and branded websites, YouTube videos, and CBS's The Early Show coverage of VSFS, were also viewed and notes on them were also taken. Further discussions and secondary analyses were conducted to deconstruct the texts into several themes informed by the male consumer gaze.

\section{Enacting the Male Consumer Gaze in VSFS and HISP}

As noted above, the body posture of a female model in an advertisement or on the runway often connotes subordination and/or sexualization. Such postures were found throughout both programs. In VSFS, the models often appeared in canting poses at the end of the runway, which can be interpreted as a sexualized twist of the body that emphasizes a diagonal posture rather than vertical one. In the first segment ("Ballet"), VS "Angel" Alessandra Ambrosio holds what is known as the "fifth position" in ballet terminology. Her arms are raised over her head, her torso is bent and one leg has a bent knee in front of the other, but she is doing this while dressed in the sexualized VS winged lingerie. Other models tug on their hair, or enact a "come hither" over-the-shoulder look. With HISP, when the first 33 Hooters Girls walk down the runway, similar to the models in VSFS, most do canting poses at the end of the runway. However, unlike VSFS, which typically features models one at a time on the runway, all one hundred contestants stay onstage during much of HISP. During the "Miss Congeniality" segment, for example, all of the Hooters Girls, in bikinis, are standing behind McGrath. They are all in the same canting pose, in which their hands are placed on one of their hips. A tag with their contestant number, placed on their bikini bottom next to their crotch, simultaneously objectified them with the numerical label and directed the gaze to that part of their body. The contestants' placement in this segment and in much of the program serves as a sexualized backdrop to McGrath and the proceedings.

Like the "live on tape" events, all televised video segments of this event showed sexualized body postures. In VSFS, several segments (such as "Show Day") offer views of the 
models in preparation with multiple hands pulling at their bodies and faces, applying costumes and makeup, as the models stand passively. HISP video segments were notably prominent with sexually provocative body postures. Photo shoots or graphics highlighting photos presumably from such shoots often show models in bikinis stroking themselves, sometimes wet, lying on their stomachs, with lips parted, in classic Goffman-defined patterns. A segment called "Hooters World Domination" emphasizes the sexualization and exoticization of the "Other" in consumer culture (Hooks 2012). The segment is teased with a backstage clip of a contestant saying, "Let's show these Americans how international girls do it," and adding prominently accented statements from contestants about the sexual variations of international women such as: "Australian girls, I think we're a different kind of sexy, I think it's more of a fun sexy, like a cheeky sexy," or: "I find Canada girls really, really hot." As the contestants say their names or comment on national sexualities in the segment, they are mostly shown in multiple canting postures in their bikinis, such as lying down on their sides or on their stomachs, in water, touching their face and hair or sitting in a slanted diagonal posture.

The sexualization of body posture is accentuated through televisual techniques. Both programs extensively used visual styles illustrative of the emphasis on cinematic technique in the male gaze. When comparing the two events, there is a bit more sophisticated and sexualized camera work of the actual event itself in VSFS than HISP, perhaps reflecting the larger budget of the former as a primetime broadcast network program and more prestigious brand. When VS models are first shown walking down the runway, for example, there were "bodyism" camera shots, such as a close-up of the legs, and quick pan ups that mimic the sexualized gaze of a body from bottom to top. Shots will occasionally start at the crotch, linger at the midriff, and end at the bust. Similarly, when the one hundred Hooters contestants were introduced, there would be an occasional camera pan up the body. However, more typical in both programs were standard full or medium shots, often straight ahead on the runway.

However, in the video segments prepared for both, the perspective of the camera as a sexualized gaze was predominant. Slow motion, close-up, bodyism shots of breasts, midriff, and legs, and pans up a body are typical. One HISP feature, about Megan Hood from "Hooters of Nottingham, UK," uses several slow pans on her bikinied body, emphasizing prominent cleavage shots. Similar techniques are used in profiles of VS models, such as Lily Aldridge, who viewers are told "loves music" as a slow-motion shot of her listening to headphones, with eyes closed and head and hair tousling back and forth, eroticizes her. Erin Heatherton is "definitely a sexy nerd," which is illustrated by sexualized slow motion technique and shots of her breasts that signify the former, while her glasses signify the latter. Such camera techniques are often accompanied by sexualized body postures featured in the first section, such as head tilts, body canting, and prone position.

Besides camera technique, the intensity of a male gaze is emphasized by visual access to normally "hidden" spaces, especially spaces that reveal the sexualized female. Both programs offer visual access to such spaces through "behind-the-scenes" features or "backstage" cutaways. In HISP, such shots often occur as the program comes back from commercial, or they are introduced by co-host Sara Hoots. Before one segment, the other co-host, McGrath, introduces it:

McGrath: It's time right now to go backstage to Sara Hoots, who I understand has the secret to these beautiful girls' beauty. [Cut to backstage.]

Hoots: What pageant is about butt glue? These ladies are going to need it, because they thought there might be some wardrobe malfunctions. As you can see, it's very highly important.

As Hoots is saying this, the camera shows a female worker applying glue to the bikini bottoms of women as the camera zooms in (right as she says, "as you can see"). A similar occurrence is displayed in VSFS, in which a model is in danger of being late to the runway because she cannot get her boots off. What viewers see are several, mostly male, hands pulling at her clothes. 
Viewers are also given access to another kind of hidden space: background stories of the models or contestants who reveal their journey to (sexualized) success. One VSFS segment shows various models looking at their childhood pictures, displaying prominent cleavage of the models as they look at the old photos. Photos of two of the models show them as children in their underwear or bikinis. "This is both our first bikini shot moment. Ha, we killed it," says one of the models. Evocating the postfeminist trend of "sexual subjectification" (Gill $2008,41)$, one segment on the models' "first time" on the runway equates being gazed at with empowerment and sexual maturity, both visually and verbally. Accompanied by shots of backstage preparation and anxiety, one model concludes, "Standing backstage in my outfit I was so nervous. But then when I stood on the runway I felt like I became a woman." This quote is followed by several quick-cut, bodyism shots on the runway, models winking at the camera. Similar themes are found in HISP. In the above-mentioned segment about UK Hooters-server Hood, she confesses: "Before I worked at Hooters, I was actually quite shy. [Cut to a cleavage shot] Now I'm like, 'Hi guys, you alright?"' [Scene ends with Hood in her Hooters outfit.]. Another is of Nikki Scott from Hooters Las Vegas, who equates "looks" with "being" in her transformation to a Hooters Girl. She says, "For quite a few years [pause], I was a very large girl. This used to be me [holding up pants and a T-shirt], this is what I look like now. Most days when I look in the mirror [looks at herself in a mirror], I see exactly who I wanted to become. So now every day when I put these shorts on, I'm proud that I can fit into them." When Scott says the word "shorts," the shot is of her rear, in Hooters shorts, as she turns around.

Body posture, camera angles and hidden access connote a male point-of-view as well as heterosexuality, as opposed to alternative sexual orientations. All this is reinforced by the role of males in the two programs. Men are gaze authority figures, highlighting the visual aspects of the women, modeling how males gaze, and enacting additional privileged gazes. We see this in the roles men play in the programs, which are the ones of host, celebrity gazer, and male authority in general.

HISP co-host McGrath, of course, is always onstage gazing at the Hooters contestants as he introduces, describes, and interviews them. Just as the male narrator of the VS network promo, discussed at the beginning of the paper, primed viewers for a male gaze, McGrath's language, befitting of a "swimsuit competition," is filled with visual metaphors when describing the contestants. During the first half of the program with all one hundred contestants onstage behind him, he explains that the contestants are "in a swimsuit of their choice, and I for one cannot wait to see what they have chosen." Later, before announcing the finalists, McGrath declares, "Now we've seen one hundred of the most beautiful Hooters Girls in the world." He labels the individual finalists with such descriptors as "brains and beauty," "Tyler, you look beautiful tonight," "the lovely Victoria." However, it is not just the female contestants he describes visually. He says of his female co-host Hoots, "Isn't she beautiful?" and of the "Orange Pride Honoree," chosen from older "Hooters Girl Alumni" who have become accomplished after leaving the restaurant, he says, "You look lovely tonight." The latter is reinforced by a video segment, which shows past photos of the accomplished Honoree in her Hooters outfit and in a bikini.

Males are also represented as gazers in other ways. For example, the mostly male judges of HISP are only occasionally shown, but their introduction at the beginning of the program, in front of the stage, signifies their continual gazing. In a later segment, in which only male judges were interviewed, Hoots asks: "What are you looking for in a Miss Hooters International?" One says, "I like the way they walk, I'm kind of a waist-down person," and the other, mimicking the first, remarks, "I've never been in a room with so many beautiful women [...], just personality. I love the way they walk." No male hosts or judges were used in VSFS, but the maleness of the gaze was signified via the program's featured male celebrities as both audience members and musical performers. A common cutaway shot, while VS models walked the runway, was of celebrity audience members - usually male - watching the models. Very early in the program, less than a minute after the first model starts her walk, there is a shot of actor Joe Manganiello (of the film Magic Mike and television series True Blood) gazing at her. Another early viewing shot is of actor Orlando Bloom as his spouse, VS Angel 
Miranda Kerr, first strolls. As the introduction to this article suggests, VS celebrity performers are given privileged gazing status. They are onstage with the models and have a close gaze. Kanye West, during his performance at one point, pauses his singing and instead focuses his gaze on a model's rear as she walks by and places his hand to his face as if he were evaluating her. As mentioned earlier, in much of their performance, both West and Jay-Z are in darkness, a stark contrast to the brightly lit models and even one of the other performers, Nicki Minaj, a singer who, similar to the VS models, spectacularizes appearance.

In both programs, male authority's gazing privileges are predominant. In VSFS, we hear a (usually) male voice with a tonal quality simulating that from an intercom system, giving stage and camera shot directions, and constructing the same "backstage access" for the viewers that these voices have. Instances of the director's voice we hear before segments include "They're still getting into costume," "We have Nicki, she is on her way to you now," and "Hurry, she's going to miss her walk, guys." In each case, the camera displays the images described by the authorial male voice.

Special authority is given to the ultimate gazers, the photographers, who are nearly all male in segments for both programs. In such segments, we watch men gazing and controlling women. Two quick segments show VS models surrounded by male photographers while one model says, without irony, "You kind of feel like a deer in headlights, your first show." Especially striking is a video segment that introduces the "Miss Photogenic" selection in HISP. It profiles several photographers, all male, and what they look for in a model. In this segment, we see several men shooting photographs of bikinied women, and commenting on that process. One says, "When a photo really stands out for us, it possesses certain characteristics. For example this was a nice shot, all the elements came together." The photo that is shown on his computer is highly sexualized, emphasizing cleavage, self-touching and a prone position: these illustrate "all the elements." Another photographer is blunter: "Of course, being a photographer I'm always looking for the beautiful face with the right booty." Interviewed women highlight the visual and, through pronouns, gendered authority of the photographers. One bikini-dressed contestant says, "The photographers are great. He'll just tell you what he wants and he'll fix it if he doesn't like it." Another adds, "the photographers are giving me good direction," while a third confirms, "he shows me the pictures so I know if I need to change and how to change it."

\section{A Flow of Commercialized Gazes}

Applying the concept of the male consumer gaze implies that advertising and promotion are essential elements of the studied texts. In fact, as forms of branded entertainment, branding was present throughout both programs, from strategically placed brand names on- and backstage, to branded apparel worn by models and contestants, to explicit promotions and commercials. Accompanying most of these were highly sexualized images of women since, of course, sexualization is a key brand element for both Victoria's Secret and Hooters.

In VSFS, the models were accompanied by the VS logo and brand name onstage and off. During the first three themed segments, the words "Victoria's Secret," arranged in a half circle, were placed onstage above a separate VS logo. As many of the winged-lingerie "Angels" paused at the end of the runway, a long-shot framed the stage-designed "Victoria's Secret" words above their heads, not unlike halos. In interview segments with the models, a glittery VS logo was placed in the background, serving as over-the-shoulder signage. Viewers also saw the VS logo on each of the Angels' famous pink robes during interviews, and the final themed segment, called "Club Pink," promoted Victoria's Secret Pink, a subsidiary brand. "Pink" was displayed in large, block letters behind Nicki Minaj and the models in later segments.

Like VSFS, HISP heavily promoted the Hooters brand with the use of logos throughout the telecast. The opening dance number for the pageant was set against the backdrop of three large television screens that displayed a Hooters logo. During the live event, prepared video segments that profiled individual Hooters Girls often featured women dressed in their traditional Hooters workplace garb: branded tight white T-shirts and orange shorts. 
Further branding occurred by integrating other Hooters merchandise, solidifying connections among the brand, merchandise and the sexual gaze. Two of the most visually sexual manifestations of Hooters merchandise, the calendar and magazine, were mentioned several times. Co-host McGrath described contestants as having been in "the 2011 and 2012 Hooters calendar and the Hooters magazine", "the 2012 Hooters calendar", and "the Hooters calendar twice." The Hooters calendar was also tied in with HISP in one "behind-the-scenes" segment of the calendar photo shoot as a female announcer explains, "Our nationwide Hooters calendar photo tour culminates here in Miami Beach Florida, where we get the chance to photograph one hundred of the most beautiful Hooters girls from around the world....The 2013 Hooters Calendar will be on sale at Hooters everywhere October 1st."

Other brand mentions included various Hooters restaurants from around the globe, its casino in Las Vegas, other Hooters televised events, such as The Hooters Dream Girl, another annual branded beauty competition, its charitable causes known as "Hooters Give Back," and its alumni program "Orange Pride." Additional visual product integration involved one male judge wearing a Hooters T-shirt, and occasional shots of the live theatre audience that showed wait staff in Hooters outfits, serving Bud Light, the sponsor of the broadcast.

The synergy of brand, gaze and retail consumerism was especially demonstrated during two segments. One occurs early in the program, when McGrath throws to his backstage cohost Sara Hoots, who is "with a very special Hooters Girl." Hoots begins by noting that Hooters Girls "like to have a little fun at work," and this is illustrated by a woman behind her in a Hooters work outfit, hula hooping. The camera and the hoop move up and down her body, pausing at her breasts. Hoots explains, "Behind me I have Heather Frank from Fairfax, Virginia who is fast becoming a YouTube sensation with over 700,000 hits for her hula hooping skills that you have to check out." The final prepared segment highlighted Lindsay Way, the 2011 HISP winner. Way explained the impact that becoming a Hooters' champion had on her, including being recognized at her place of work, a Hooters Restaurant in Fort Lauderdale, Florida. One camera shot featured Way standing outside of the restaurant next to a billboard showcasing her as the 2011 winner. She explains how her swimsuit crown affected her workplace experience, when she holds up - and the camera zooms into - a page of the Hooters menu with two images of her, one in a Hooters outfit and the other on the cover of the calendar in a bikini: "People that would sit with me, the customers, they'd open it [the menu], 'is that you?'" In this way, the retail space - a work place - becomes an object of the triple gaze for this "winner": as a Hooters server, as a canted-legged branded beauty winner, and as a calendar cover girl, the latter literally for sale with other items on the menu.

The prominent branding messages in the two programs complement the product advertising aired during them and reinforce the privilege of the male consumer gaze by creating a "flow of gazing signifiers" in promos, programs, and commercials. With VSFS, this gazing flow began with the network promotion, described at the beginning of this article and aired again before the end credits of the previous program (NCIS). The accompanying commercials that most obviously signify a thematic flow of the male consumer gaze are those for VS products. Five commercials for VS-branded products aired during VSFS, spaced throughout the program. One commercial in particular distilled the program's male-gaze style into 30 seconds. It features slow-motion shots, underweared VS models, extreme close-ups of the face, tilted cameras, a shot through a partition (which indicated "to-be-looked-at-ness"), self touching, such as fingers in mouth and lingering shots of the breasts. It ends with a woman walking toward the camera, slow motion, with a Victoria's Secret logo overlay. Although no men are seen in the ad, its soundtrack is the male-sung Sinatra standard "In the Wee Hours of the Morning", about a man's obsession with a woman, thus adding a hovering male presence throughout the ad. A later commercial, for the official VSFS T-shirt, shows three models in the T-shirts walking by a subway train with simulated photography flashes going off. In the commercial, an announcer promised an extended and privileged gaze via official online sites: "Victoria's Secret thanks you for watching this year's show presentation. For more behindthe-scene footage, model biographies and other extras, log onto victoriassecret.com /fashionshow." 
No official Hooters commercials aired during HISP, but many third-party product ads had strong themes of the legitimacy and authority of the male gaze upon sexualized women. This was particularly true for ads for the official sponsor of the telecast, Bud Light. As the program goes into the first commercial break, a female announcer touts that HISP "is brought to you by Bud Light. It's the sure sign of a good time. Here we go." This is immediately followed by a Bud Light ad featuring the rapper Pitbull in a nightclub, being handed a Bud Light by a "flirty" waitress. He looks into the camera and says "Darling," twisting off the cap to his Bud Light bottle. This literally twists the waitress as well (www.youtube.com/watch?v=ZW15yMEMwcM at $0: 11$ ), transforming her clothes from casual to shorter or skimpier and her hair from pinned up to disheveled shoulder length. As Pitbull walks through the club, he gazes at other women (signified by tilting his sunglasses). Other men twist their beer caps, and the women are likewise sexually altered. When, later in the ad, the women twist open their own beers, nothing happens. No men are transformed, except as delighted gazers of the newly sexualized women. At the end, Pitbull's gaze alone, like male photographers portrayed during both programs, causes the transformation.

Another Bud Light ad later in the telecast highlights alcohol and partying in the workplace: "They say a man's work is never done. They say you can't mix business.... with pleasure. They say good things come, to those who wait. It's a good thing 'they' don't work here." The last shot is of a raucous party in a business office viewed literally through a Bud Light bottle. A third ad shows male office workers using Bud Light to create an absurdly expansive party in an office-building elevator, with bikinied women strolling out at one point. The Bud Light ads not only consistently emphasized the link between alcohol and transformative female sexuality, but also the sexualization of retail and work places, a theme that, disturbingly, flowed consistently with messages of HISP and Hooters as a brand.

\section{Extending the Gaze: Integrating Social and Synergistic Media}

Commodity flow is not simply limited to promotional activity on one television channel, but may also be an intermedia practice (McAllister and Giglio 2005). In this case, the gazefocused branding of the programs was extended by the integrated marketing of ancillary social and synergistic media to promote the events and the broadcasts, and to cultivate fan involvement. Social media, such as Facebook and YouTube, and more traditional media owned or controlled by the corporate brands or their promotional partners, including the websites of the brands and the television networks, were framed and enacted to extend the gaze of the presumed male fans of the brand, giving them yet more privileged and sexualized views.

HISP especially made use of social media as part of the integrated campaign for the program. The Hooters Official Channel on YouTube and the Hooters Facebook page prominently promoted the program and offered additional video clips, searchable on the site, explicitly tied into the program (all YouTube and Facebook media accessed on June 25, 2012). This included additional "behind-the-scenes" footage of the week leading up to the pageant, such as a minute-long promotional video featuring a series of extended sexualized shots, no dialogue, and ending with a graphic that connects the retail space to the gaze: "Watch it at your local Hooters" (a message also reinforced on the Facebook page). Another is the previously mentioned 3-minute "Hooters Girl Hula Hooper," tying in with the brief live-action display viewers saw backstage during the program, and directing viewers to the Hooters YouTube channel.

Most extensive is a 54-minute video, "The 2012 Miss Hooters International Swimsuit Contestants," which presents each of the one hundred contestants in succession dancing or posing. The video solidifies the connection between sexualization and the branded retail space. Each contestant is dressed in her Hooters workplace outfit and shot against a background that resembles a table in a Hooters restaurant. In some cases, the contestants engage in provocative activities such as hula hooping or self-touching, and/or pantomime their workplace duties, in many cases offering to the camera bottles of Bud Light, the program's sponsor. Each is introduced by a graphic with her number and name, but throughout, the contest- 
ants are silent, with only music as the audio. Viewers are informed on the sites that they may use this video profile to decide their vote for the "Hooters Viewer's Choice Winner."

VSFS used social media in a similar way to post additional "behind-the-scenes" videos of the event's preparation, but in addition, VSFS also used, for several years, the various news divisions of CBS and its local affiliate stations to promote the program. This is especially evident in tie-in "plugola" news stories that air the morning of the broadcast on the CBS's The Early Show, a category of promotional news that is characteristic of brand- and advertisingoriented media corporations (McAllister 2002). The airing of plugola for VSFS has been the practice of CBS for several years. In the case of the 2011 VSFS, two segments were devoted to the upcoming program, both featuring in-studio interviews with two of the participating Victoria's Secret models (The Early Show 2011). In the tease for the promotional segments, the female anchor highlights the male appeal of the segment and the in-studio visit:

Erica Hill: And the Victoria's Secret Fashion Show features thirty-eight models, thirtyone pairs of wings [footage of VSFS, with the graphic "Coming Up Heaven Sent"]. Jeffrey Glor: Yep.

Hill: And aren't you lucky, especially the gentlemen on the crew here. Two of the models will be with us in the studio to preview tonight's big event. Stay with us. You're watching The Early Show on CBS.

Glor: For two segments, not just one.

Hill: Two, two segments, Jeff.

A later tease emphasizes a similar male-oriented theme, with perhaps a hint of the tension placed on news personnel by both sexualized and promotional news:

Hill: Also ahead, a couple of Victoria's Secret Angels are stopping by. Yes, they're going to be here... [footage of VSFS, models on the runway].

Glor: Yep.

Hill: ...for two segments, Jeffrey would like you to know.

Glor: Getting some help with our 401(k)'s [referring to another segment].

Hill: Adriana Lima, who's been here a few times. Always very sweet.

Glor: Yes, she is very sweet.

Hill: And Candice, how do you say, Jeff? Swanepoel.

Glor: There you go.

Hill: They're here to preview tonight's big Victoria's Secret Fashion Show, which you will only see here on CBS. It's a rather glitzy party. This year, as you can see, Kanye-on hand to perform.

Glor: Why are you assuming I'm the expert on this? [Back to a shot of the two smiling hosts].

Hill: Because you've been talking about it all morning. In fact, I think you started talking about it yesterday.

Glor: Last week?

Hill: No, I said yesterday, but maybe you did start talking about it last week.

Glor: That's not true.

Hill: I don't know, maybe I should call your wife and ask her.

Glor: Primetime, it's a big fashion show. We're gonna...

Hill: It's on our network.

Glor: ...give you all the details.

Hill: And so we are promoting...

Glor: Give you everything you need.

Hill: ...everything in it.

Other segments discuss VSFS's visual and exclusive nature, with footage from the program often accompanying the segments. Hill says, for example, "...so many people will be watching. The fashion is decidedly on the skimpy side." And later she seems to downplay interpre- 
tations of her earlier comments as critical, and emphasize the legitimate appeal of the program's visual spectacle, in her interview with two models: "It's amazing, the production too, I mean, this isn't just, we sort of joke around, beautiful women, you know, not, not too much that they are wearing, but this is, it's an incredible thing to watch." One of the interviewed models, Candice Swanepoel, says how eager she is to watch the final version "because they show so much more than just the show. It's, it's about our lives and what goes on behind the scenes. It's really interesting to see."

In one exchange about how the models stay in shape, the male gaze of the moving female body is jokingly alluded to, but in a way not dissimilar to the more irony-free "hula hooping" of HISP contestants:

Adriana Lima: You know, um, l've been boxing for like six years.

Glor: Boxing?

Swanepoel: Six years, yeah.

Lima: It's just like part of my routine, I love it. So that's what I like to do, jumping rope.

Hill: $\mathrm{Mm}-\mathrm{Hm}$.

Glor: Oh.

Swanepoel: She can jump rope for like an hour and a half without stopping.

Lima: I love it.

Glor: Can we have a jump rope? [He looks out to the crew when he asks this].

Lima: Not too big, so I have heels on. I don't have the proper-

Swanepoel: I'm sure you can do it in the heels, as well.

\section{Conclusion}

As seen above, the two studied media artifacts were characterized by a confluence of visual and verbal messages that reinforced a male consumer gaze. Such characteristics were found in the programs themselves, the commercials accompanying the programs, and the social and synergistic media used to promote and extend the programs. To what extent might the textual characteristics of male consumer-gazing influence audience readings of such gendered forms of branded entertainment? Web-based media, including social media, although often primarily a key marketing tool, offer a measure (even if an imperfect one) of audience impact, as illustrated in user comments on YouTube, Facebook, and other feedbackoriented websites. Scholarship has already noted a tendency of young users on social media to duplicate gendered advertising tropes when they post self-photographs (Tortajada, Araüna, and Martínez 2013). Future research may analyze user and fan comments on such sites about the extent to which such comments use language or themes that reflect or criticize dominant gazing and branding.

The changing nature of media economics, technology, and integrated and niche marketing - the latter involving increasing integration of knowledge about audience and consumer behaviour (Turow 2006) - may exacerbate such trends. For example, focusing on the increase of male-targeted cable and satellite outlets devoted to sports (the NFL Network, Speed, Untamed Sports TV, and multiple manifestations of ESPN and Fox Sports), highlights the increasingly gendered nature of entertainment and marketing. Each of these channels, in term, is supported by a complex of promotional partners and social digital media outlets, and look to advertisers for program development and support.

Not only does this trend call for the need of academics to document and analyze their ideological and political implications critically, but it also calls for the adaptability of theoretical and analytical concepts. As commercialism integrates into various forms of culture, bringing with it new or intensified ideological meanings, scholars should be prepared to morph scholarly tools to understand the depth and nuance of these phenomena.

\section{References}

Amy-Chinn, Dee. 2006. This is Just for Me(n): Lingerie Advertising for the Post-Feminist Woman. Journal of Consumer Culture 6(2): 155-175. 
Andersen, Robin. 2002. The Thrill Is Gone: Advertising, Gender Representation, and the Loss of Desire. In Sex \& Money: Feminism and Political Economy in the Media, edited by Eileen R. Meehan and Ellen Riordan, 223-239. Minneapolis: University of Minnesota Press.

Andersen, Robin. 2008. Hypercommercialism. In Battleground: The Media, Vol. 1, edited by Robin Andersen and Jonathan Gray, 171-181. Westport: Greenwood Press.

Annual Report. 2012. Limited Brands. Accessed August 1, 2013. http://www.limitedbrands.com/investors/annual report/AnnualReport.aspx

Baltruschat, Doris. 2011. Branded Entertainment and the New Media Economy. In The Propaganda Society: Promotional Culture and Politics in Global Context, edited by Gerald Sussman, 45-60. New York: Peter Lang.

Berger, John. 1972. Ways of Seeing. New York: Penguin.

Bettig, Ronald V. and Jeanne Hall. 2012. Big Media, Big Money: Cultural Texts and Political Economics, 2nd ed. Lanham, MD: Rowman and Littlefield.

Budd, Mike, Steve Craig and Clay Steinman. 1999. Consuming Environments: Television and Commercial Culture. New Brunswick, NJ: Rutgers University Press.

Caputi, Jane. 1999. The Pornography of Everyday Life. In Mediated Women: Representations in Popular Culture, edited by Marian Meyers, 57-79. New York: Hampton Press.

Christians, Clifford G. and James W. Carey. 1989. The Logic and Aims of Qualitative Research. In Research Methods in Mass Communication, edited by Guido H. Stempel III and Bruce H. Westley, 354-374. Englewood Cliffs, NJ: Prentice Hall.

Cooper, Brenda. 2001. Unapologetic Women, "Comic Men" and Feminine Spectatorship in David E. Kelley's Ally McBeal. Critical Studies in Media Communication 18 (4): 416-435.

De Lauretis, Teresa. 1984. Alice Doesn't: Feminism, Semiotics, Cinema. Bloomington: Indiana University Press.

Doane, Mary Ann. 1982. Film and the Masquerade: Theorizing the Female Spectator. Screen, 23 $(3 / 4): 74-88$.

Foss, Sonja K. and Karen A. Foss. 1994. The Construction of Feminine Spectatorship in Garrison Keillor's Radio Monologues. Quarterly Journal of Speech 80 (4): 410-426.

Gill, Rosalind. 2008. Empowerment/Sexism: Figuring Female Sexual Agency in Contemporary Advertising. Feminism \& Psychology 18: 35-60.

Goffman, Erving. 1979. Gender Advertisements. New York: Harper \& Row.

Grimes, Sara M. 2013. From Advergames to Branded Worlds: The Commercialization of Digital Gaming. In The Routledge Companion to Advertising and Promotional Culture, edited by Matthew P. McAllister and Emily West, 386-399. New York: Routledge.

Guthrie, Marisa. 2011. How 'Victoria's Secret Fashion Show' Turns \$12 Million into \$5 Billion in One Hour. Hollywood Reporter, November 28. Accessed August 1, 2013. http://www.hollywoodreporter.com/news/victorias-secret-fashion-cbs-266665.

Hall, Christine C. I. and Matthew J. Crum. 1994. Women and "Bodyisms" in Television Beer Commercials. Sex Roles, 31 (5/6): 329-337.

Helford, Elyce Rae. 2006. The Stepford Wives and the Gaze: Envisioning Feminism in 1975. Feminist Media Studies 6 (2): 145-156.

Hocker Rushing, Janice. 1998. Putting Away Childish Things: Looking at Diana's Funeral and Media Criticism. Women's Studies in Communication 21 (2): 150-167.

Hooks, Bell. 2012. Eating the Other: Desire and Resistance. In Media and Cultural Studies: Keyworks, 2nd ed., edited by Meenakshi Gigi Durham and Douglas M. Kellner, 308-317. Malden, MA: WileyBlackwell.

Hooters 2012 International Swimsuit Pageant. 2012. Directed by Bob Mckinnon. Dallas, TX: FX Cable Television Network, television program, June 23 [original airing].

Hooters Franchising. 2012. Hooters. Accessed August 1, 2013. http://www.hooters.com/Company/franchise.aspx .

Juffer, Jane. 1996. A Pornographic Femininity? Telling and Selling Victoria's (Dirty) Secrets. Social Text, 48 (14): 27-48.

Kilbourne, Jean. 1999. Deadly Persuasion: Why Women and Girls Must Fight the Addictive Power of Advertising. New York: The Free Press.

Kite, Lexie. 2011. From Objectification to Self-Subjectification: Victoria's Secret as Do-it-Yourself Guide. Paper presented at the annual meeting of the National Communication Association, New Orleans, November 17-20. 
Lehu, Jean-Marc. 2007. Branded Entertainment: Product Placement and Brand Strategy in the Entertainment Business. London: Kogan Page.

McAllister, Matthew P. 2002. Television News Plugola and the Last Episode of Seinfeld. Journal of Communication 52 (2): 383-401.

McAllister, Matthew P. and J. Matt Giglio. 2005. The Commodity Flow of U.S. Children's Television. Critical Studies in Media Communication 22 (1): 26-44.

McChesney, Robert W. 1999. Rich Media, Poor Democracy: Communication Politics in Dubious Times. Urbana, IL: University of Illinois Press.

Merskin, Debra. 2006. Where Are the Clothes? The Pornographic Gaze in Mainstream American Fashion Advertising. In Sex in Consumer Culture, edited by Tom Reichert and Jacqueline Lambiase, 199-217. New York: Erlbaum.

Middleton, Jason. 2007. Buffy as Femme Fatale: The Cult Heroine and the Male Spectator. In Undead TV: Essays on Buffy the Vampire Slayer, edited by Elana Levine and Lisa A. Parks, 145-167. Durham: Duke University Press.

Morrison, Maureen. 2012. Hooters: We're More than Wings Gone Wild. Advertising Age, July 31. Accessed August 24, 2012. http://adage.com/article/news/hooters-lure-women-diners/236418/

Mulhern, Frank. 2009. Integrated Marketing Communications: From Media Channels to Digital Connectivity. Journal of Marketing Communications, 15 (2/3): 85-101.

Mulvey, Laura. 1975. Visual Pleasure and Narrative Cinema. Screen, 16 (3): 6-18.

National Football League Game. 2011. New York: CBS Broadcast Television Network, television program. November 27 [original airing].

Nowak, Anita, Sue Abel and Marjan deBruin, M. 2010. Contextualizing Women/Advertising/ Representation. In Women, Advertising and Representation: Beyond Familiar Paradigms, edited by Sue Able, Marjan deBruin and Anita Nowak, 11-27. New York: Hampton.

Oates, Thomas P. 2007. The Erotic Gaze in the NFL Draft. Communication \& Critical/Cultural Studies, 4 (1): 74-90.

O'Connell, Michael. 2011. TV Ratings: 'Victoria's Secret Fashion Show' Rakes in Record Ratings at CBS. Hollywood Reporter, November 30. http://www.hollywoodreportercom/live-feed/tv-ratingsvictorias-secret-fashion-show-tuesday-267554 Accessed August 1, 2013.

Patches, Matt. 2011. The 5 Best Moments from the Victoria's Secret Fashion Show. Hollywood.com, November 29. Accessed August 1, 2013.

http://www.hollywood.com/news/Victorias_Secret_Fashion_Show_5_Best_Moments/9815779

Patterson, Maurice and Richard Elliot. 2002. Negotiating Masculinities: Advertising and the Inversion of the Male Gaze. Consumption, Markets \& Culture 5 (3): 231-249.

Pfeiffer, Alice. 2012. Editing as a Brand Investment. The New York Times. Retrieved from http://www.nytimes.com/2012/02/22/fashion/22iht-rbrand22.html? r $r=0$.

Rudy, Rena M., Lucy Popova and Daniel G. Linz. 2011. Contributions to the Content Analysis of Gender Roles: An Introduction to a Special Issue. Sex Roles, 64 (3/4): 151-159.

Shields, Vickie R. 1990. Advertising Visual Images: Gendered Ways of Seeing and Looking. Journal of Communication Inquiry 14: 25-39.

Shields, Vickie R. and Dawn Heinecken. 2002. Measuring Up: How Advertising Affects Self-Image. Philadelphia: University of Pennsylvania Press.

Stacey, Jackie. 1987. Desperately Seeking Difference. Screen 28 (1): 48-61.

Stern, Danielle M. 2005. MTV, Reality Television, and the Commodification of Female Sexuality in The Real World. Media Report to Women 33 (2): 13-21.

The 2012 Hooters International Swimsuit Contestants. 2012. Video. Accessed August 1, 2012. http://www.youtube.com/watch?v=IMaOUxqKzOU

The Codes of Gender: Identity and Performance in Pop Culture. 2009. Directed by Sut Jhally. Northampton, MA: Media Education Foundation, video. The Early Show. 2011. New York: CBS Broadcast Television Network, television program, November 29 [original airing].

Tortajada, Iolanda, Núria Araüna and Inmaculada J. Martínez. 2013. Advertising Stereotypes and Gender Reproduction in Social Media Sites. Comunicar 41: 177-186.

Turow, Joseph. 2006. Niche Envy: Marketing Discrimination in the Digital Age. Cambridge, MA: MIT Press.

Valdivia, Angharad N. 1997. The Secret of My Desire: Gender, Class, and Sexuality in Contemporary Lingerie Catalogs. In Undressing the Ad: Reading Culture in Advertising, edited by Katherine T. Frith, 225-250. New York: Peter Lang. 
Victoria's Secret Fashion Show. 2011. Directed by Hamish Hamilton. New York: CBS Broadcast Television Network, television program, November 29 [original airing].

Williams, Raymond. 1975. Television: Technology and Commodity Form. New York, NY: Schocken.

Williamson, Judith. 1978. Decoding Advertisements. London: Marion Boyars.

\section{About the Authors}

Matthew P. McAllister

is a professor of Communications in the Department of Film/Video \& Media Studies at Pennsylvania State University, USA. He is the co-editor, with Emily West, of The Routledge Companion to Advertising and Promotional Culture (2013).

Lauren J. DeCarvalho

is a Visiting Assistant Professor at the University of Arkansas, USA. She has a BA in Journalism, an MA in Media Studies, and a PhD in Mass Communications, all from Pennsylvania State University. Her research focuses on representational issues of women in film and television. 